\title{
Orexin and Alzheimer's Disease: A New Perspective
}

\author{
Yoo Hyun Um and Hyun Kook Lim $\bowtie$ \\ Department of Psychiatry, College of Medicine, The Catholic University of Korea, Seoul, Republic of Korea
}

\begin{abstract}
Orexin's role in human cognition has recently been emphasized and emerging evidences indicate its close relationship with Alzheimer's disease $(\mathrm{AD})$. This review aimed to demonstrate recent research on the relationship between orexin and AD. Orexin's role in stress regulation and memory is discussed, with significant findings related to sexual disparities in stress response, with potential clinical implications pertaining to $\mathrm{AD}$ pathology. There are controversies regarding the orexin levels in $\mathrm{AD}$ patients, but the role of orexin in the trajectory of $\mathrm{AD}$ is still emphasized in recent literatures. Orexin is also accentuated in the context of tau pathology, and orexin as a potential therapeutic target for $\mathrm{AD}$ is frequently discussed. Future directions with regard to the relationship between orexin and $\mathrm{AD}$ are suggested: 1) consideration for $\mathrm{AD}$ trajectory in the measurement of orexin levels, 2) the need for objective measure such as polysomnography and actigraphy, 3) the need for close observation of cognitive profiles of orexin-deficient narcolepsy patients, 4) the need for validation studies by neuroimaging 5) the need for taking account sexual disparities in orexinergic activiation, and 6) consideration for orexin's role as a stress regulator. The aforementioned new perspectives could help unravel the relationship between orexin and AD.

Psychiatry Investig 2020;17(7):621-626
\end{abstract}

Key Words Orexin, Dementia, Alzheimer's disease, Cognition.

\section{INTRODUCTION}

Orexin (also named hypocretin) is a neuropeptide, and their function is implemented by two G-protein-coupled receptors. Two subtypes exist, orexin A and orexin B, and they are synthesized by neurons located in lateral hypothalamus and perifornical areas. ${ }^{1}$ Orexin has been described in many literatures as a key neuropeptide regulating fundamental brain functions, including arousal, appetite, stress and cognition, ${ }^{2-6}$ playing a major role in the homeostatic control of our body state. Orexin neurons project to various brain regions, including prefrontal cortex, hippocampus, thalamus, hypothalamus, locus coeruleus, raphe nuclei, parabrachial nuclei, central gray and nucleus tractus solitaries, and the aforementioned sites have crucial functions regarding cognitive processes and their consequences. ${ }^{8}$ Orexin has not only been emphasized as an integral research topic in sleep research, but also in neuropsychiatry. ${ }^{4,9}$ Indeed, abundant research reported orexin's in-

Received: April 16, 2020 Revised: May 5, 2020

Accepted: May 12, 2020

$\triangle$ Correspondence: Hyun Kook Lim, MD, PhD

Department of Psychiatry, Yeouido St. Mary's Hospital, College of Medicine,

The Catholic University of Korea, 10 63-ro, Yeongdeungpo-gu, Seoul 07345, Republic of Korea

Tel: +82-2-3779-1048, Fax: +82-2-780-6577, E-mail: drblues@catholic.ac.kr

(c) This is an Open Access article distributed under the terms of the Creative Commons Attribution Non-Commercial License (https://creativecommons.org/licenses/bync/4.0) which permits unrestricted non-commercial use, distribution, and reproduction in any medium, provided the original work is properly cited. tegral role in human cognition and its relationship with $\mathrm{Al}$ zheimer's disease (AD). Therefore, in this review, we will demonstrate what has been reported to be the role of orexin in the pathology of $\mathrm{AD}$, and provide future research directions pertaining to this field.

\section{OREXIN AS A STRESS REGULATOR AND ITS RELATIONSHIP WITH COGNITION}

With regard to the relationship between orexin and cognition, recent emphasis on orexin's role as a stress regulator should not be dismissed. ${ }^{10-12}$ Indeed, a recent study indicated that rats adopted a passive coping behavior after social defeat stress through orexin activation, which induced recognition memory impairments..$^{13}$ Orexinergic blockade in the hippocampus reversed stress-induced anxiety behaviors and memory deficits in rats, which suggested potentials of hippocampal orexins as therapeutic targets to minimize stress-induced impairments. ${ }^{14}$ A sexual disparity was noted with regard to orexin's role in stress response, a female rat displaying more vulnerability to repeated stress, demonstrating prominent impairments in habituation and cognitive flexibility, with increased orexin expression when compared with male rats. ${ }^{15}$ In rat models, orexin-A was closely related to the expression of corticotroping releasing factor (CRF), ${ }^{16}$ and when infusion of orexin-B receptor antagonist was implemented, it significantly reduced stress- 
induced adenocorticotropin (ACTH). ${ }^{17}$ Lower orexin levels were correlated with increased resilience to social stress, ${ }^{18}$ while a contrasting result indicated that orexin increased stress resilience by reducing depressive behaviors. ${ }^{11}$ Orexin-A antagonist inhibited a stress response via fronto-hippocampal circuit, including amygdala. ${ }^{19}$ Orexin is also involved in reinforcing norepinephrine-mediated long term potentiation in dentate gyrus, exerting its critical role in attention and memory. ${ }^{20}$ The hippocampal-amygdala interactions were modulated by orexinergic receptors, with orexinergic receptor blockade in the basolateral amygdala induced long-term potentiation in the dentate gyrus. ${ }^{21}$ Therefore, a mediating role of orexin could exert great influence on the process of emotional learning. ${ }^{21}$ Indeed, orexin was closely related to fear memory, with negative associations between orexin A level and fear extinction. ${ }^{22}$

Independent of orexin's role as a stress regulator, orexin's role in cognition and memory and learning is frequently discussed. Orexin-deficient mice exhibited slowed decreased spatial-cue related working memory, when compared to control mice. ${ }^{23}$ In a rat model, both types of orexin exerted their effects on spatial learning and memory through orexin 1 receptor, which extends their projection to hippocampal formation. ${ }^{24}$ Orexin might exert a considerable influence on attention as well, with results on attention-deficit and hyperactivity disorder (ADHD) patients, showing decreased serum orexin A levels in human subjects. ${ }^{25}$ The relationship between cholinergic transmission and orexin has also been discussed frequently. Activation of basal forebrain by orexinergic neurons, and their critical role in arousal and attention are well-known. ${ }^{26-28}$ Orexinergic nerouns and both orexin receptor subtypes are distributed in the basal forebrain, and fine modulation of cholinergic system is mediated through orexinergic control ${ }^{27,28}$ Such control is suggested to be mediated by gamma oscillations. ${ }^{29}$ Orexin A is purported to directly influence cholinergic neurotransmission in hippocampus, with lack of response to orexin A noted in aged rats. ${ }^{30}$ Differentiating disparate olfactory cues is another important role of orexinergic innervation in the basal forebrain. ${ }^{31}$

As with regard to its relationship with medial prefrontal cortex (MPFC), orexinergic receptor signaling was purported to be crucial in potentiating cognitive motivation to eat. ${ }^{32} \mathrm{~A}$ recent report proposed that high fat diet fed, orexin-deficient mice exhibit impaired cognition and increased microglial activation when compared with controls. ${ }^{33}$ Moreover, hypocretin in MPFC reinforces cortical arousal and attention closely related to limbic states. ${ }^{34}$ Indeed, orexin is closely associated with dopamine efflux within prefrontal cortex, specifically through dopaminergic neurons in ventral tegmental area. ${ }^{35,36}$

Orexinergic neurons are lost with aging, ${ }^{37}$ and its role in agerelated cognitive decline is increasingly emphasized. Age-re- lated cognitive decline and orexin are discussed in consideration for orexin's role in appetite. Age-related loss of orexinergic neurons could contribute to impairments in orexinergic modulation of hippocampal neurochemistry. ${ }^{38}$ Despite the aforementioned studies that imply important clinical implications, most recent results on the relationship between orexin and cognition have been limited to animal studies. Further human studies are needed to confirm the exact role of orexin in regulating various cognitive pathways.

\section{A CRUCIAL LINK BETWEEN OREXIN AND ALZHEIMER'S DISEASE}

A link between orexin and $\mathrm{AD}$ has been mostly discussed in the context of explaining the bidirectional relationship between $\mathrm{AD}$ and sleep disturbance. ${ }^{39}$ A recent research suggested that amyloid deposition affects memory by its effect on sleep, but how amyloid affects sleep and consequent memory disruption remains elusive. ${ }^{40}$ Orexin may be an important mediating factor that could explain this ambiguity. However, contradicting results exist regarding the orexin levels in $\mathrm{AD}$ patients. A postmortem study concluded that reduced cerebrospinal fluid (CSF) orexin A levels and orexinergic neuronal cell numbers were found in advanced AD patients. ${ }^{41}$ Meanwhile, orexin level was increased in moderate to severe $\mathrm{AD}$ patients, when compared with mild AD or healthy controls. ${ }^{42}$ Hippocampal overexpression of orexin did not have any association with amyloid beta $(A \beta)$ deposition, when $A \beta$ aggregation increased when orexinergic neurons were rescued in amyloid precursor protein (APP)/Presenilin1 (PS1) transgenic mice. ${ }^{43}$ Moreover, there was no difference in orexin levels between $\mathrm{AD}$ patients and healthy controls, and the orexin levels did not reach statistical significance with regard to apolipoprotein E 4 (ApoE4) genotype. ${ }^{44}$ In one study with consideration for a diurnal variation of orexin levels, orexin levels did not differ between $\mathrm{AD}$ patients and the control group, and lower $\mathrm{A} \beta$ levels were associated with a higher amplitude of orexin circadian rhythm. ${ }^{45}$ In a recent study on investigation of the relationship between partial sleep deprivation and CSF parameters pertaining to $\mathrm{AD}$-related neurodegeneration, there was a significant increase noted in orexin levels after partial sleep deprivation, while other parameters remained insignificant. ${ }^{46}$

The role of orexin with regard to the importance of sleepwake cycle in the trajectory of $\mathrm{AD}$ is frequently demonstrated. Orexin has an integral role in promoting wakefulness in mammals, with cessation of its neuronal firing during sleep. ${ }^{3}$ Increased research is directed to understanding the sleep-wake cycle and its control of $A \beta$ levels in brain interstitial fluid. ${ }^{47}$ Soluble $A \beta$ has been purported to be a major culprit for inducing neurotoxic effects resulting in synaptic loss and dysfunc- 
tion, and the sleep-wake cycle is predicted to play a major role in the clearance of soluble $A \beta .^{48}$ Orexinergic signaling has been suggested as a major pathway for hippocampal circadian oscillation that is suspected to exert a considerable influence on the expression of $\mathrm{AD}$-risk genes that play a major role in production and transport of $A \beta{ }^{49}$ Excessive orexinergic signaling is purported to be a culprit for causing sleep-wake cycle disruption that hastens $A \beta$ deposition. ${ }^{50}$ In line with this proposition, interstitial fluid $A \beta$ levels increased with orexin infusion and decreased with orexin antagonist in one study. ${ }^{51}$ There was a study where orexin disrupted degradation of $A \beta$ by microglia. ${ }^{52}$

Orexin is also discussed in the context of tau pathology, ${ }^{53}$ with orexin levels proportionally increased with total tau protein (T-tau) levels in $\mathrm{AD}$ patients. Moreover, orexin showed a positive relationship with phosphorylated tau (P-tau) levels in cognitively normal elderly subjects, even when controlled for years of education and ApoE4 status. ${ }^{42}$ In a mouse model, orexin knockdown resulted in inhibition of T-tau and P-tau levels, with adenosine A receptor showing a close expression level with orexin. ${ }^{54}$ Tau proteins usually represent brain neuronal injury subsequent to $\mathrm{AD}$ pathology, and how orexin exerts its influence on tau-mediated neuronal injury remains ambiguous. Many possible mechanisms were proposed through which orexin exerts pernicious effects that hasten $\mathrm{AD}$ pathology. In an AD mice model, orexin A aggravated mitochondrial impairment. ${ }^{55}$ Genetic vulnerability might be another culprit, with one study suggesting orexin receptor 2 gene could be a risk factor for $\mathrm{AD}{ }^{56}$ With regard to neuronal injury and orexin, a few of recent findings present a potential candidate for future research directions. Orexin has been suggested as one important potential neuropeptide in the modulation of the metaplasticity in the brain, with evidences for fine modulation of long-term potentiation and long-term depression in animal models. ${ }^{57}$ Recently, orexinergic innervations were discovered in the adult rat subventricular zone, which is the site for active neurogenesis..$^{58}$

\section{OREXIN AS A POTENTIAL THERAPEUTIC TARGET FOR ALZHEIMER'S DISEASE}

Orexin, with key previously published findings on its relationship with $\mathrm{AD}$, has been discussed as a potential therapeutic target for $\mathrm{AD}$. Orexin $\mathrm{A}$ and $\mathrm{B}$ treatment both regulated the hippocampal oscillator, which is suggested to play a major role the circadian control of Alzheimer's disease-risk genes. ${ }^{49}$ With regard to emphasis on understanding of orexin in consideration for its role in sleep modulation, ${ }^{43}$ orexin antagonist is an interesting target of research in patients at risk or suffering from
AD. Suvorexant, an orexin antagonist approved by FDA with indications on insomnia patients, can be utilized in future clinical trials to unravel $A \beta$ dynamics. ${ }^{47}$ Indeed, almorexant, another type orexin antagonist, reduced interstitial $A \beta$ levels during the light period. ${ }^{51}$ Delivery methods of therapeutic effects of orexin are another matter in discussion. Orexin gene delivery through lentiviral vector was suggested as a study modality to explore the relationship between orexin and $\mathrm{AD}$, and such method could be applied to the development of new therapeutic agents. ${ }^{59}$ Intranasal delivery is another option, with a recent review demonstrating intranasal administration of orexin effectively increasing neuronal activation in an animal model. ${ }^{60}$

\section{FUTURE DIRECTIONS IN RESEARCH ON THE RELATIONSHIP BETWEEN ALZHEIMER'S DISEASE AND OREXIN}

Several important considerations are necessary in the future research regarding the link between $\mathrm{AD}$ and orexin. First, orexin level changes with regard to $\mathrm{AD}$ trajectory will be conducive to understanding the interactive link between orexin and $\mathrm{AD}$ pathology. Indeed, a recent research on change of CSF tau, neurofilament light and YKL-40 levels compared between groups in different phases of $\mathrm{AD}$ trajectory provided a valuable insight into a potential CSF biomarker that could be utilized in clinical settings. ${ }^{61}$ The same approach could be applied to orexin measured from CSF, thus understanding how orexin affects the $\mathrm{AD}$ pathology longitudinally.

Second, quantification of orexin levels, along with objective sleep studies including polysomnography and actigraphy, should be used to accurately reflect the sleep-wake cycle and sleep patterns among elderly population. Third, cognitive profiles and longitudinal observation of narcolepsy patients, with consideration for the incidence of $\mathrm{AD}$ in this particular group will be integral to understanding the link between $A D$ and orexin. In sleep research, orexin has remained a central research arena for narcolepsy, with key findings that reported its major relationship with pathophysiology of narcolepsy. Mutations in orexin receptor gene were discovered in canine narcolepsy cases,${ }^{62}$ and subsequent reports demonstrated deficient orexin level in narcolepsy patients. ${ }^{63}$ In a recent report, when compared with controls, type 1 narcolepsy patients exhibited reduced amyloid deposition. ${ }^{64}$ Moreover, neurodegenerative CSF biomarkers, including A $\beta$, T-tau and P-tau levels were reduced in narcolepsy patients, when compared with healthy individuals. ${ }^{65}$ Whether narcolepsy patients' orexin-deficient status is a protective factor for $\mathrm{AD}$ should be explored in further studies.

Fourth, orexin level studies should be implemented along 
with validation studies with utilization of neuroimaging modalities. Indeed, a recent paper published an article defining cutoff values of CSF biomarkers defined by positron emission tomography (PET) status. ${ }^{66}$ Orexin levels measured in different phases of $\mathrm{AD}$ trajectory, with their relationship with PET and neural networks manifested by magnetic resonance imaging (MRI) will provide a novel insight into the relationship between $\mathrm{AD}$ and orexin.

Fifth, the relationship between orexin and female hormones will provide an interesting research arena in exploring the link between $\mathrm{AD}$ and orexin. Female sex is a well-known risk factor for $\mathrm{AD}$, and searching for gender-specific predictors of $\mathrm{AD}$ is a major research field that deserves more clinical attention. ${ }^{67}$ As mentioned before earlier in this article, a sexual disparity was noted in orexin expression levels, demonstrated in rats, with female displaying more vulnerability to stress and increased orexin activation. ${ }^{15}$ Neuroprotective effects of estrogen, inherent vulnerability of female brain to $\mathrm{AD}$, and a recent research findings of estrogen receptor localization of neurofibrillary tangles are all intriguing topics under discussion, ${ }^{68,69}$ but most previous studies on the effects of estrogen replacement therapy on $\mathrm{AD}$ prevention are disappointing. ${ }^{70}$ The relationship between sleep and estrogen has been reported frequently, ${ }^{71-74}$ and in consideration for the integral role of orexin during wake and sleep states, investigations on the mediating role of orexin in $\mathrm{AD}$ pathology and sleep in female patients are needed. Inhibitory effects of estrogen on orexin A was reported in one study, ${ }^{75}$ and orexin A was reported to be responsible for progesterone secretion in a sheep model. How female hormones, sleep and $\mathrm{AD}$ pathology interact could be a new pathway to understanding $\mathrm{AD}$ trajectory.

Lastly, orexin plays a critical role as a stress regulator, and the relationship between orexin and cognition is often in the context of stress. A recent review reported accumulated evidences supporting oxidative stress evoked by prolonged wakefulness, increasing neuronal oxidative damage. ${ }^{76}$ Orexin a wake promoter, and the relationship between reactive oxygen specifies and orexin levels in normal controls without AD pathology, preclinical dementia, mild cognitive impairment, $\mathrm{AD}$ patients will be conducive to unravelling the orexin's role as a stress regulator and its impact on cognition.

\section{CONCLUSION}

In this review, we have presented recent, updated evidences for the relationship between orexin and $\mathrm{AD}$ pathology. Many previous literatures suggested sleep as a modifiable risk factor for $A D,{ }^{77-80}$ with emphasis on early intervention for those in the $\mathrm{AD}$ trajectory. However, still, there is no clear-cut model to understand the role of sleep in the course of $\mathrm{AD}$ pathology.
Orexin, a major neurotransmitter regulating sleep, stress and appetite, may have a direct or indirect effect that could help uncover the relationship between sleep and AD. Further well-designed prospective studies are needed to explicate the link between orexin, sleep and cognition, adopting more diverse research methods and multifaceted understanding of orexin.

\section{Acknowledgments}

This work was supported by the National Research Foundation of Korea (NRF) grant funded by the Korea government (MSIT) (No. 2018R1D1A1 A02049615).

\section{Conflicts of Interest}

The authors have no potential conflicts of interest to disclose.

\section{Author Contributions}

All authors have contributed to the present review with equal efforts.

\section{ORCID iDs}

Yoo Hyun Um

Hyun Kook Lim

https://orcid.org/0000-0002-3403-4140

https://orcid.org/0000-0001-8742-3409

\section{REFERENCES}

1. Willie JT, Chemelli RM, Sinton CM, Yanagisawa M. To eat or to sleep? Orexin in the regulation of feeding and wakefulness. Annu Rev Neurosci 2001;24:429-458.

2. Burdakov D. How orexin signals bias action: hypothalamic and accumbal circuits. Brain Res 2020;1731:145943.

3. Mavanji V, Perez-Leighton CE, Kotz CM, Billington CJ, Parthasarathy S, Sinton CM, et al. Promotion of wakefulness and energy expenditure by orexin-A in the ventrolateral preoptic area. Sleep 2015;38:1361-1370.

4. Prober DA. Discovery of hypocretin/orexin ushers in a new era of sleep research. Trends Neurosci 2018;41:70-72.

5. Soya S, Sakurai T. Orexin as a modulator of fear-related behavior: hypothalamic control of noradrenaline circuit. Brain Res 2020;1731:146037.

6. Summers CH, Yaeger JDW, Staton CD, Arendt DH, Summers TR. Orexin/hypocretin receptor modulation of anxiolytic and antidepressive responses during social stress and decision-making: Potential for therapy. Brain Res 2020;1731:146085.

7. Burdakov D. Reactive and predictive homeostasis: roles of orexin/hypocretin neurons. Neuropharmacology 2019;154:61-67.

8. Song J, Kim E, Kim CH, Song HT, Lee JE. The role of orexin in post-stroke inflammation, cognitive decline, and depression. Mol Brain 2015;8:16.

9. Chen Q, de Lecea L, Hu Z, Gao D. The hypocretin/orexin system: an increasingly important role in neuropsychiatry. Med Res Rev 2015;35:152197.

10. Grafe LA, Bhatnagar S. Orexins and stress. Front Neuroendocrinol 2018; 51:132-145.

11. Ji MJ, Zhang XY, Chen Z, Wang JJ, Zhu JN. Orexin prevents depressivelike behavior by promoting stress resilience. Mol Psychiatry 2019;24:282293.

12. Sargin D. The role of the orexin system in stress response. Neuropharmacology 2019;154:68-78.

13. Eacret D, Grafe LA, Dobkin J, Gotter AL, Renger JJ, Winrow CJ, et al. Orexin signaling during social defeat stress influences subsequent social interaction behaviour and recognition memory. Behav Brain Res 2019;356:444-452.

14. Bahramzadeh Zoeram S, Elahdadi Salmani M, Lashkarbolouki T, Goudarzi I. Hippocampal orexin receptor blocking prevented the stress induced social learning and memory deficits. Neurobiol Learn 
Mem 2019;157:12-23.

15. Grafe LA, Cornfeld A, Luz S, Valentino R, Bhatnagar S. Orexins mediate sex differences in the stress response and in cognitive flexibility. Biol Psychiatry 2017;81:683-692.

16. Al-Barazanji KA, Wilson S, Baker J, Jessop DS, Harbuz MS. Central orexin-A activates hypothalamic-pituitary-adrenal axis and stimulates hypothalamic corticotropin releasing factor and arginine vasopressin neurones in conscious rats. J Neuroendocrinol 2001;13:421-424.

17. Chang H, Saito T, Ohiwa N, Tateoka M, Deocaris CC, Fujikawa T, et al. Inhibitory effects of an orexin-2 receptor antagonist on orexin A- and stress-induced ACTH responses in conscious rats. Neurosci Res 2007;57: 462-466.

18. Grafe LA, Eacret D, Dobkin J, Bhatnagar S. Reduced orexin system function contributes to resilience to repeated social stress. eNeuro 2018;5.

19. Gozzi A, Lepore S, Vicentini E, Merlo-Pich E, Bifone A. Differential effect of orexin- 1 and CRF-1 antagonism on stress circuits: a fMRI study in the rat with the pharmacological stressor Yohimbine. Neuropsychopharmacology 2013;38:2120-2130.

20. Walling SG, Nutt DJ, Lalies MD, Harley CW. Orexin-A infusion in the locus ceruleus triggers norepinephrine (NE) release and NE-induced long-term potentiation in the dentate gyrus. J Neurosci 2004;24:74217426.

21. Ardeshiri MR, Hosseinmardi N, Akbari E. Orexin 1 and orexin 2 receptor antagonism in the basolateral amygdala modulate long-term potentiation of the population spike in the perforant path-dentate gyrus-evoked field potential in rats. Neurobiol Learn Mem 2018;149:98-106.

22. Shi L, Chen W, Deng J, Chen S, Han Y, Khan MZ, et al. Orexin A differentially influences the extinction retention of recent and remote fear memory. Front Neurosci 2018;12:295.

23. Dang R, Chen Q, Song J, He C, Zhang J, Xia J, et al. Orexin knockout mice exhibit impaired spatial working memory. Neurosci Lett 2018; 668:92-97.

24. Akbari E, Naghdi N, Motamedi F. The selective orexin 1 receptor antagonist SB-334867-A impairs acquisition and consolidation but not retrieval of spatial memory in Morris water maze. Peptides 2007;28:650656.

25. Baykal S, Albayrak Y, Durankuş F, Güzel S, Abbak Ö, Potas N, et al. Decreased serum orexin A levels in drug-naive children with attention deficit and hyperactivity disorder. Neurol Sci 2019;40:593-602.

26. Blake MG, Boccia MM. Basal forebrain cholinergic system and memory. Curr Top Behav Neurosci 2018;37:253-273.

27. Fadel J, Burk JA. Orexin/hypocretin modulation of the basal forebrain cholinergic system: role in attention. Brain Res 2010;1314:112-123.

28. Fadel J, Frederick-Duus D. Orexin/hypocretin modulation of the basal forebrain cholinergic system: insights from in vivo microdialysis studies. Pharmacol Biochem Behav 2008;90:156-162.

29. Ishibashi M, Gumenchuk I, Kang B, Steger C, Lynn E, Molina NE, et al. Orexin receptor activation generates gamma band input to cholinergic and serotonergic arousal system neurons and drives an intrinsic $\mathrm{Ca}(2+)$ dependent resonance in LDT and PPT cholinergic neurons. Front Neurol 2015;6:120.

30. Stanley EM, Fadel J. Aging-related deficits in orexin/hypocretin modulation of the septohippocampal cholinergic system. Synapse 2012;66: 445-452.

31. Piantadosi PT, Holmes A, Roberts BM, Bailey AM. Orexin receptor activity in the basal forebrain alters performance on an olfactory discrimination task. Brain Res 2015;1594:215-222.

32. Cole S, Keefer SE, Anderson LC, Petrovich GD. Medial prefrontal cortex neural plasticity, orexin receptor 1 signaling, and connectivity with the lateral hypothalamus are necessary in cue-potentiated feeding. J Neurosci 2020;40:1744-1755.

33. Duffy CM, Hofmeister JJ, Nixon JP, Butterick TA. High fat diet increases cognitive decline and neuroinflammation in a model of orexin loss. Neurobiol Learn Mem 2019;157:41-47.
34. Huang H, Ghosh P, van den Pol AN. Prefrontal cortex-projecting glutamatergic thalamic paraventricular nucleus-excited by hypocretin: a feedforward circuit that may enhance cognitive arousal. J Neurophysiol 2006;95:1656-1668.

35. Vittoz NM, Berridge CW. Hypocretin/orexin selectively increases dopamine efflux within the prefrontal cortex: involvement of the ventral tegmental area. Neuropsychopharmacology 2006;31:384-395.

36. Vittoz NM, Schmeichel B, Berridge CW. Hypocretin /orexin preferentially activates caudomedial ventral tegmental area dopamine neurons. Eur J Neurosci 2008;28:1629-1640.

37. Kessler BA, Stanley EM, Frederick-Duus D, Fadel J. Age-related loss of orexin/hypocretin neurons. Neuroscience 2011;178:82-88.

38. Fadel JR, Jolivalt CG, Reagan LP. Food for thought: the role of appetitive peptides in age-related cognitive decline. Ageing Res Rev 2013;12:764776.

39. Villa C, Ferini-Strambi L, Combi R. The synergistic relationship between Alzheimer's disease and sleep disorders: an update. J Alzheimers Dis 2015;46:571-580.

40. Lucey BP, Holtzman DM. How amyloid, sleep and memory connect. Nat Neurosci 2015;18:933-934.

41. Fronczek R, van Geest S, Frölich M, Overeem S, Roelandse FWC, Lammers GJ, et al. Hypocretin (orexin) loss in Alzheimer's disease. Neurobiol Aging 2012;33:1642-1650.

42. Liguori C, Romigi A, Nuccetelli M, Zannino S, Sancesario G, Martorana A, et al. Orexinergic system dysregulation, sleep impairment, and cognitive decline in Alzheimer disease. JAMA Neurol 2014;71:1498-1505.

43. Roh JH, Jiang H, Finn MB, Stewart FR, Mahan TE, Cirrito JR, et al. Potential role of orexin and sleep modulation in the pathogenesis of Alzheimer's disease. J Exp Med 2014;211:2487-2496.

44. Schmidt FM, Kratzsch J, Gertz HJ, Tittmann M, Jahn I, Pietsch UC, et al. Cerebrospinal fluid melanin-concentrating hormone $(\mathrm{MCH})$ and hypocretin-1 (HCRT-1, orexin-A) in Alzheimer's disease. PLoS One 2013; 8:e63136.

45. Slats D, Claassen JA, Lammers GJ, Melis RJ, Verbeek MM, Overeem S. Association between hypocretin- 1 and amyloid- $\beta 42$ cerebrospinal fluid levels in Alzheimer's disease and healthy controls. Curr Alzheimer Res 2012;9:1119-1125.

46. Olsson M, Ärlig J, Hedner J, Blennow K, Zetterberg H. Sleep deprivation and cerebrospinal fluid biomarkers for Alzheimer's disease. Sleep 2018;41.

47. Musiek ES, Xiong DD, Holtzman DM. Sleep, circadian rhythms, and the pathogenesis of Alzheimer disease. Exp Mol Med 2015;47:e148.

48. Van Egroo M, Narbutas J, Chylinski D, Villar González P, Maquet P, Salmon E, et al. Sleep-wake regulation and the hallmarks of the pathogenesis of Alzheimer's disease. Sleep 2019;42. pii: zsz017.

49. Ma Z, Jiang W, Zhang EE. Orexin signaling regulates both the hippocampal clock and the circadian oscillation of Alzheimer's disease-risk genes. Sci Rep 2016;6:36035.

50. Liguori C. Orexin and Alzheimer's disease. Curr Top Behav Neurosci 2017;33:305-322.

51. Kang JE, Lim MM, Bateman RJ, Lee JJ, Smyth LP, Cirrito JR, et al. Amyloid-beta dynamics are regulated by orexin and the sleep-wake cycle. Science 2009;326:1005-1007.

52. An H, Cho MH, Kim DH, Chung S, Yoon SY. Orexin impairs the phagocytosis and degradation of amyloid-beta fibrils by microglial cells. J Alzheimers Dis 2017;58:253-261.

53. Holth J, Patel T, Holtzman DM. Sleep in Alzheimer's disease-beyond amyloid. Neurobiol Sleep Circadian Rhythms 2017;2:4-14.

54. Liu Z, Wang F, Tang M, Zhao Y, Wang X. Amyloid $\beta$ and tau are involved in sleep disorder in Alzheimer's disease by orexin A and adenosine A(1) receptor. Int J Mol Med 2019;43:435-442.

55. Li M, Meng Y, Chu B, Shen Y, Xue X, Song C, et al. Orexin-A exacerbates Alzheimer's disease by inducing mitochondrial impairment. Neurosci Lett 2020;718:134741.

56. Gallone S, Boschi S, Rubino E, De Martino P, Scarpini E, Galimberti D, 
et al. Is HCRTR2 a genetic risk factor for Alzheimer's disease? Dement Geriatr Cogn Disord 2014;38:245-253.

57. Peineau S, Rabiant K, Pierrefiche O, Potier B. Synaptic plasticity modulation by circulating peptides and metaplasticity: involvement in $\mathrm{Al}-$ zheimer's disease. Pharmacol Res 2018;130:385-401.

58. Arias-Carrion O, Ortega-Robles E, de Celis-Alonso B, Palasz A, Mendez-Rojas MA, Salas-Pacheco J, et al. Depletion of hypocretin/orexin neurons increases cell proliferation in the adult subventricular zone. CNS Neurol Disord Drug Targets 2018;17:106-112.

59. Roh J, Holtzman DM. Lentiviral Vector Delivery of Orexin Gene to Study Potential Role of Orexin and Sleep Modulation in the Pathogenesis of Alzheimer's Disease. In: Li M, Snider BJ, Editors. Gene Therapy in Neurological Disorders. Elsevier, Academic Press, 2018, p.163-175.

60. Calva CB, Fadel JR. Intranasal administration of orexin peptides: mechanisms and therapeutic potential for age-related cognitive dysfunction. Brain Res 2020;1731:145921

61. Lleó A, Alcolea D, Martínez-Lage P, Scheltens P, Parnetti L, Poirier J, et al. Longitudinal cerebrospinal fluid biomarker trajectories along the Alzheimer's disease continuum in the BIOMARKAPD study. Alzheimers Dement 2019;15:742-753.

62. Lin L, Faraco J, Li R, Kadotani H, Rogers W, Lin X, et al. The sleep disorder canine narcolepsy is caused by a mutation in the hypocretin (orexin) receptor 2 gene. Cell 1999;98:365-376.

63. Kornum BR, Faraco J, Mignot E. Narcolepsy with hypocretin/orexin deficiency, infections and autoimmunity of the brain. Curr Opin Neurobiol 2011;21:897-903.

64. Gabelle A, Jaussent I, Bouallègue FB, Lehmann S, Lopez R, Barateau L, et al. Reduced brain amyloid burden in elderly patients with narcolepsy type 1. Ann Neurol 2019;85:74-83.

65. Jennum PJ, Østergaard Pedersen L, Czarna Bahl JM, Modvig S, Fog K, Holm A, et al. Cerebrospinal fluid biomarkers of neurodegeneration are decreased or normal in narcolepsy. Sleep 2017;40.

66. Hansson O, Seibyl J, Stomrud E, Zetterberg H, Trojanowski JQ, Bittner T, et al. CSF biomarkers of Alzheimer's disease concord with amyloid- $\beta$ PET and predict clinical progression: a study of fully automated immunoassays in BioFINDER and ADNI cohorts. Alzheimers Dement 2018; 14:1470-1481.

67. Lyu J, Kim HY. Gender-specific incidence and predictors of cognitive impairment among older Koreans: findings from a 6-year prospective cohort study. Psychiatry Investig 2016;13:473-479.

68. Wang C, Zhang F, Jiang S, Siedlak SL, Shen L, Perry G, et al. Estrogen receptor- $\alpha$ is localized to neurofibrillary tangles in Alzheimer's disease. Sci Rep 2016;6:20352.

69. Pike CJ. Sex and the development of Alzheimer's disease. J Neurosci Res 2017;95:671-680.

70. Merlo S, Spampinato SF, Sortino MA. Estrogen and Alzheimer's disease: still an attractive topic despite disappointment from early clinical results. Eur J Pharmacol 2017;817:51-58.

71. Tansupswatdikul P, Chaikittisilpa S, Jaimchariyatam N, Panyakhamlerd $\mathrm{K}$, Jaisamrarn U, Taechakraichana N. Effects of estrogen therapy on postmenopausal sleep quality regardless of vasomotor symptoms: a randomized trial. Climacteric 2015;18:198-204.

72. Joffe H, Crawford SL, Freeman MP, White DP, Bianchi MT, Kim S, et al. Independent contributions of nocturnal hot flashes and sleep disturbance to depression in estrogen-deprived women. J Clin Endocrinol Metab 2016;101:3847-3855.

73. Gervais NJ, Mong JA, Lacreuse A. Ovarian hormones, sleep and cognition across the adult female lifespan: an integrated perspective. Front Neuroendocrinol 2017;47:134-153.

74. McHill AW, Klerman EB, Slater B, Kangarloo T, Mankowski PW, Shaw ND. The relationship between estrogen and the decline in delta power during adolescence. Sleep 2017;40.

75. El-Sedeek M, Korish AA, Deef MM. Plasma orexin-A levels in postmenopausal women: possible interaction with estrogen and correlation with cardiovascular risk status. BJOG 2010;117:488-492.

76. Macedo AC, Balouch S, Tabet N. Is sleep disruption a risk factor for Alzheimer's disease? J Alzheimers Dis 2017;58:993-1002.

77. Minakawa EN, Wada K, Nagai Y. Sleep disturbance as a potential modifiable risk factor for Alzheimer's disease. Int J Mol Sci 2019;20. pii: E803.

78. Spira AP, Gottesman RF. Sleep disturbance: an emerging opportunity for Alzheimer's disease prevention? Int Psychogeriatr 2017;29:529-531.

79. Shi L, Chen SJ, Ma MY, Bao YP, Han Y, Wang YM, et al. Sleep disturbances increase the risk of dementia: a systematic review and meta-analysis. Sleep Med Rev 2018;40:4-16.

80. Mander BA, Winer JR, Jagust WJ, Walker MP. Sleep: a novel mechanistic pathway, biomarker, and treatment target in the pathology of Alzheimer's disease? Trends Neurosci 2016;39:552-566. 